\title{
INFORMATIONAL WORLDVIEW. SCIENTIFIC FOUNDATIONS, AND PHILOSOPHICAL PERSPECTIVES
}

\begin{abstract}
In the text, I synthetically discuss the cultural background, computer science basis, and philosophical potential of an informational worldview, which I treat as an indirect link between awareness of the significance of contemporary achievements of computer science (its theories and applications) and the philosophy of future (informatism) based on the concept of information. Within the philosophical and cognitive science thread of this work, I focus on informationally-driven questions about the mind (its informational content and computational strategies of modelling) and the complexity of the world (which is directly related to the complexity of problems in which the mind is involved).

Keywords: algorithm, code, computability, information processing, computational modelling, informational worldview, general informatics.
\end{abstract}

\section{Introduction}

In the text, I would like to discuss synthetically the concept of informational worldview, to which not even a short study in English has been devoted yet. This concept corresponds to a general vision of the world according to which basic computer science categories - such as algorithms, data or automata - are treated as a valuable starting point for the description of non-technical phenomena. Since I call this vision a worldview, I would like to start with an explication of how I understand the concept of worldview itself (still without the attribute "informational"). ${ }^{1}$

First of all, situating this concept on a psychological plane, it should be stated that a worldview is a personal phenomenon, a group of individual convictions shared by a specific person and related to such basic issues (and general issues at the same time) as the structure and cognizability of 


\section{Pawel Stacewicz}

the world, the nature of the mind, the system of fundamental values, etc. Metaphorically speaking, this is a kind of small philosophy of a specific person; philosophy that has a crucial influence on one's life choices and decisions.

On the other hand, moving from specific people to the communities created by them, it should be said that a worldview is a social phenomenon: a type of opinion (on the subjects already mentioned) which is quite well established in a given community and time (period). Understood this way, the worldview can be a starting point for developing a systematic philosophy - moderately coherent, expressed through technical terms, and mostly related to a historical trend (for example Aristotelianism or Kantianism).

As can be observed in the above terms, I want to treat worldview as something close to philosophy: on the one hand, as a small personal philosophy of a specific man, and on the other hand, as a socially established introduction to a systematically practised philosophy. Due to the accumulation of various questions that combine both philosophy and science, this text is closer to the second intention.

Finally, I would like to explain the convention of presentation which I have adopted. Following the principle of maximum conciseness of text, I have divided it into short, "encyclopaedic" points - the main points (from 1 to 13) constitute the core of the exposition (reading the text for the first time, one can focus only on them), whereas subpoints are composed of short developments and comments on the core. I would also like to explain that due to such "economical" convention, I could not introduce all issues connected with the informational worldview; they are discussed in detail in the book, written in Polish, Umyst - Komputer - Swiat. $O$ zagadce umystu z informatycznego punktu widzenia [Mind - Computer World. On the Riddle of the Mind from the Informational Point of View], as well as in two academic blogs: Cafe Aleph (which I co-edit in Polish) and Our Pub (edited by Witold Marciszewski in English). The aim of this article is to extract from these (mainly Polish) sources the most important information, especially that which is close to cognitive research on the mind. ${ }^{2}$

1. Informational worldview (IWV) is for me certain types of pre-philosophical opinions ${ }^{3}$ that are scientifically grounded and originate from a strong conviction that the concept of information (and the related concepts) plays an essential role in the description of the world and humanworld relations. Such opinions could not have been formed until the Infor- 
mation Age, thoroughly permeated with information (perceived as a real good) and techniques (mainly computer) which enable its processing.

1.1. According to a technological criterion of the division of human civilisation development stages (each stage is determined by a defining technology; see for example (Bolter 1984)), the Information Age was preceded by: a) the Agricultural Age - dominated by manual technologies used mostly in agriculture, and b) the Industrial Age - dominated by techniques and devices to transform energy; that is, mainly engines. In both periods, some simple techniques of information processing were known, for example in the form of abacuses or arithmometres, however, they were not dominant (as it happens in the Information Age).

1.2. The year 1936 - when Alan Turing formulated his famous idea of a universal computing machine, being a theoretical foundation for future algorithmic and computer techniques (Turing 1936) - can be regarded as the symbolic beginning of the Information Age. In the same year, some other works on the subject were also published by E. Post and A. Church, and before them by K. Gödel (1931).

1.3. A practical invention (unlike Turing's construction which was strictly theoretical) that allowed the new era to come into existence, and today conditions its development, is a digital computer. A contemporary complement of this invention is the Internet, which has transformed individual computers into systems that are able to cooperate on the global scale.

1.4. Regardless of some engineering constructs and mathematical ideas that support them, it is fundamental discoveries in biology concerning the informational content of living organisms (genes, the DNA code, mechanisms of inheritance, the evolutionary scheme of development) that contributed to the emergence of the Information Age.

2. The psychological (more broadly: social) basis of IWV is the awareness, characteristic of the Information Age, that is informational awareness. It has two basic varieties, which do not have to appear simultaneously in specific people:

(i) technological awareness - related to the use of different data processing devices, mainly computers (this is a narrow dimension of informational awareness);

(ii) (pre)philosophical awareness - built on the conviction that going far beyond any object created by human beings (artefacts), the concepts of information and information processing system concern also organisms, the human mind, and social structures (it is a broad dimension of informational awareness). 


\section{Pawet Stacewicz}

Each of these varieties of informational awareness has three components:

(a) cognitive - more or less extensive theoretical knowledge about methods of obtaining, storing, processing, and transferring information and its use;

(b) axiological - conviction about the fact that having information and knowledge about its essence as well as presenting some IT skill are goods/values that one should strive for;

(c) practical - connected with the effective use of knowledge about information and information processing systems. ${ }^{4}$

2.1. Although informational awareness could develop to the full only in the second half of the $20^{\text {th }}$ century (dominated by electronic data processing technologies), its traces - which we can call informational preawareness - can be observed in the whole history of human civilisation. Both its signs and fruits constitute groundbreaking inventions that are milestones in civilisation's progress: language, numeral systems, writing, abacus, library, printing (all are used to record and transfer information in some form).

2.2. The most shallow form of informational awareness manifests itself in knowledge of some "common" facts about information and information processing techniques. For example: a) information is something that describes and represents (for example in computer memory) objects existing in the world; b) the simplest way to record information, used for example in digital computers, is zero-one notation; c) in every cell of an organism, there is a code (the DNA code) that conditions its development.

2.3. The deepest form of informational awareness requires solid knowledge of logical and mathematical basis of contemporary data processing techniques and their limitations (for example the fact that there are some problems unsolvable with the use of digital techniques).$^{5}$

2.4. A mature form of informational awareness is connected with the idea of rationality, significant for human culture, which is the driving force of Western civilisation and manifests itself in the systematic pursuit of knowledge, its consolidation and application to new problems.

This "civilisation" relationship corresponds to an important conceptual relationship between the concept of information and the concept of knowledge: knowledge would be a well-justified piece of information; that is, a necessary element of the pursuit of knowledge would be obtaining information. ${ }^{6}$

3. The psychological boundary between [informational] awareness and an individual [informational] worldview is not sharp: a worldview is of rather 
Informational Worldview. Scientific Foundations, and Philosophical...

an overall character; it concerns all (or sufficiently many) aspects of reality and requires having (by a given individual) both technological and philosophical awareness that also encompasses all three components (cognitive, axiological, and practical).

4. There is no doubt that the informational worldview (IWV) - understood as both a concretum (a group of opinions of a specific person) and an abstraction (a type of opinion) - derives from scientific reflection (mainly connected with mathematics, logic, computer science, physics, and biology) and leans towards philosophy (which is a more systematic and specialised perspective, embedded, moreover, in the history of this discipline).

4.1. The fact that the IWV is spread between philosophy (that is very close to the worldview-related issues) and science (above all, informationoriented sciences like computer science; which is indicated by the first part of the term) is expressed in the very term "informational worldview".

4.2. Probably the oldest scientific idea (more precisely: mathematical), which is fundamental for an IWV, is the idea of digital coding (formulated in an incipient form by the ancient Pythagoreans). It opened the door to the future expansion of computers - that is, machines which operate on numeric codes that represent very diverse objects.

4.3. There is a feedback effect between the IWV and exact science. On the one hand, the results of some sciences influenced the formation of IWV, but on the other hand, it is the IWV which conditions the informational way of thinking in some sciences (for example in biology or psychology) and has an influence on the emergence of new disciplines (for example, cognitive science).

4.4. A typically philosophical feature of IWV is the fact that it is constituted not only by some key concepts (see point 5) and general theses, but, above all, by some open questions (for example "What is information?" a fundamental question; "Can all forms of cognition be realised artificially with the use of digital techniques of data processing?" - a question related to artificial intelligence research).

5. Nowadays, the most important science that the IWV refers to is computer science (understood in both technical and theoretical ways) with its three principal concepts: information (data), algorithm, and automaton.

On its cognitive level, the essence of IWV is a tendency to describe/explain the greatest possible number of phenomena (technical, biological, mind-related, social) in terms of the already-mentioned concepts (and also concepts related to or constructed upon them). 
6. The most important computer science concepts that are fundamental to the IWV are interrelated through a net of the following meanings:

a. Data processing system is an automaton that processes data in an algorithmic (that is, programmed) way.

b. Data are pieces of information coded in a way that is adequate to the possibilities of the automaton which processes them (for example, digital or analogue).

c. Some data (the so-called control codes) have causative power, which can be understood in the following way: adequate sequences of code symbols elicit (on account of the construction of the automaton) adequate actions of an automaton.

d. An algorithm is a scheme of operations which can be performed by a data processing machine: d1) a universal Turing machine, UTM (an algorithm understood in a narrow, although the most accurate, sense); d2) any machine (an algorithm understood in a broader sense, de facto in an open way).

e. Algorithms - used to solve definite classes of problems - have different (time and memory) complexity that is the measure of their effectiveness. The characteristic of complexity is also attributed to problems themselves: the complexity of the $\mathrm{P}$ problem is the complexity of the most effective (that is, the least complex) algorithm from all algorithms which solve the $\mathrm{P}$ problem.

f. Even in the domain of clearly defined problems (only they are the domain of computer science), there are uncomputable problems, that is those which are algorithmically unsolvable:

f1) unsolvable in principle - when an algorithm that solves all particular cases of a given problem does not exist (in an objective sense); or

f2) unsolvable in practice - when for a given problem an algorithm with sufficiently low time complexity does not exist. ${ }^{7}$

g. Depending on the adopted model of computation/algorithmisation (for example the Turing or another), we can talk about different types of computability (and uncomputability). Problems solved with the UTM are called t-computable, whereas those solved with machines of another type are called nt-computable or hyper-computable.

h. Computational power of a specific type of machine (for example digital computer; the machine type depends on the model of computation attributed to it) is the range of problems it can solve.

7. A broad interpretation of the above-mentioned technical concepts (see from $6 \mathrm{a}$ to $6 \mathrm{~h}$ ) - which is characteristic of IWV - leads to diverse theses 
and questions concerning the mind and the world. They become reasonable (and comprehensible) provided that we provisionally assume that: (a) the mind is an information processing system, (b) some fragments of the world (or even the whole world) have a specific informational content (a control code) that conditions their structure and operation. ${ }^{8}$

7.1. Simultaneously, a broad interpretation of the above-mentioned technical concepts reduces general concepts to technical concepts. Metaphorically speaking, generalisation and reduction meet as if halfway.

7.2. The assumption (a) is characteristic of such disciplines as cognitive psychology or cognitive science (where the mind is defined as an information processing system), whereas the assumption (b) is certainly related to living organisms that have a DNA code conditioning their development.

7.3. Assumption (b) seems broader than (a) because the mind is a fragment of the world; however, considering the extraordinary properties of the mind (being not only a fragment of the world, but, above all, a fragment of subjects experiencing the world), assumptions (a) and (b) should be differentiated.

7.4. A distant prototype of the assumption (b), which is crucial for the IWV, seems to be Aristotle's theory of hylomorphism (every substance consists of matter and form) and the conception of form included in it (especially form as a peculiar algorithm, cf. also the structure of the word "information": "in-form-ation") .9

8. According to the order of assumptions mentioned in point 7 , in the centre of IWV, there is a riddle of the human mind which, on the one hand, resembles artificial data processing systems (computers) and, on the other hand, has a cognitive (in a broader meaning: practical) advantage over them.

8.1. The statement that the human mind resembles a computer can be justified by the analyses of many cognitive activities (such as reasoning, proving, learning) which indicate that such activities are of an algorithmic character - that is, consist in a systematic and effective processing of adequately matched symbols (cf. for example (Lindsay, Norman 1972)). This is also justified by successful computer realisations of such activities; they are the object of a special branch of computer science, called artificial intelligence (which will be discussed later).

8.2. On the other hand, at the present stage of the development of civilisation the mind has a clear advantage over a computer, which is evidenced by the fact that in our times, it is man who is the originator, creator, and programmer of data processing systems (and not the reverse). In short: 


\section{Pawel Stacewicz}

data processing systems are products and instruments of the human mind. Will it be always like this and are there any serious obstacles on the road to creating autonomous machines/systems? - this is one of the questions asked within the IWV. ${ }^{10}$

8.3. The riddle of the human mind is reinforced by the fact that until now, there has not been any field of science that can explain convincingly such properties/functions of the mind as: consciousness, ingenuity, or cognitive intuition. And it may seem that these functions determine the cognitive effectiveness of a human. ${ }^{11}$

9. From the general scientific point of view, the best insight into the riddle of the mind can be obtained through the construction and analysis of (scientific) mind models.

From a narrower, that is informational, point of view (which is the essence of IWV), the computational strategy of mind modelling - according to which the mind is modelled as one data processing system or another is regarded as the most appropriate.

9.1. It is convenient to understand the scientifically studied mind (also: computationally modelled one) as a complex cognitive system which includes the brain as its subsystem (the mind and the brain are not separate systems; the brain can be defined as the biological basis of the mind).$^{12}$

9.2. The computational strategy of mind modelling has different variants determined by different types of information processing systems that model the mind. Among them, there are rule-based (logicistic), networkbased (connectionist), and evolutionary systems.

9.3. Computational mind models are partial models; that is, they concern particular (frequently isolated) cognitive activities such as perceiving, reasoning, or learning. ${ }^{13}$

10. Understanding and/or modelling the mind computationally, it is necessary to make an assumption that the information which fills the mind is coded in a determined way. Therefore, it is assumed that a mental code (MC) exists. Similarly to codes for computing machines, it is a control code and it also can be reflected (at least approximately) in numbers. ${ }^{14}$

10.1. Like in the case of computing machines, a $\mathrm{MC}$ has to occur in at least two forms: (a) static - about the code of data being processed, like for example sensory or mental data; (b) dynamic - about the code of schemes (algorithms) responsible for data processing (this is a control code). 
10.2. Making an assumption that the code of an individual mind can be reflected in numbers, or even recorded (using a coding method) as one huge super number, we encounter different questions about the nature of this number.

Two questions come to the fore: (a) "Is it a rational or irrational number?," and (b) "Is it a computable or uncomputable number?" Question (b) makes sense if we admit irrational MCs.

10.3. Relating these questions to mental phenomena (described by one number or another), we come to the conclusion that they concern the extremely important issue of the discreteness/continuity of the mental domain.

This can be expressed in the following question: "Are mental phenomena discrete (if they were discrete, they could be described with computable numbers that make up a countable, thus discrete set), or are they continuous (if they were continuous, the uncomputable numbers that make up an uncountable thus continuous set would be essential for their description)?". ${ }^{15}$

11. The methodological advantage of computational models of mind consists in the fact that they describe a very important, if not the most important, function of the mind, which is problem solving (data processing systems serve to solve properly-coded problems).

Due to computational constructions and models, it has been possible to gain precise knowledge about different levels (classes) of the complexity and computability of problems that the human mind has to face (very often supported by a computer).

11.1. It is generally acknowledged that problem solving is the domain of human intelligence (according to one definition, "intelligence is the same as the ability to solve problems"). For this reason, the best source of mind models is a strictly computational, artificial intelligence research (divided into a number of branches and detailed fields of research).

11.2. The existence of uncomputable problems (see point $6 \mathrm{f}$ ), and thus the existence of formal limitations of data processing techniques, can make us assume a thesis about the supermachine power of the human mind that can overcome, or at least identify, such limitations.

11.3. Writing about overcoming limitations, I mean two issues: (a) solving practically uncomputable problems (those with a high time/space complexity) in a rough way that is enough for practical reasons; (b) devising new models of computation (algorithms) under which uncomputable problems become computable (to mention for example the model of analogue computation). ${ }^{16}$ 


\section{Pawet Stacewicz}

12. From the problem complexity perspective, two cultural phenomena, related to each other, become visible: (a) the complexity of problems in the modern world is constantly growing; however, at the same time (b) the computational power of information processing systems (which support people in solving these problems) is continually increasing.

12.1. In consequence of this relationship, a significant, worldviewrelated question appears whether the rise of computational power of information processing systems "keeps pace with" the rise of problem complexity. Apart from general YES (the second process follows the first) or NO (the first process is "faster" divergent to infinity) answers, other more subtle variants are possible. Among them, there is this (pessimistic) variant that if the mind is cognitively/algorithmically equivalent to digital computers, some problems will always remain unsolvable for it.

12.2. An optimistic version of informational worldview can be contrasted with the opinion expressed in the last sentence (above): the human mind builds knowledge not only algorithmically, but also intuitively - when the algorithmic method (connected for example with specific types of algorithms) encounters difficulties, cognitive intuition activates and generates new concepts or new types of algorithms (thus increasing the cognitive power of mind) ${ }^{17}$

12.3. It should be noted that computer science itself (or its instruments) is responsible for the above-mentioned complexity of problems that is growing in the modern world. For example, a new (partly online) phenomenon of information overload or even information chaos has emerged. Related to this phenomenon, there is a significant problem of proper selection of information and its effective verification.

13. The described philosophical issues related to the informational worldview make us assume that with the passing of time, a systematic philosophy based on generalised informational concepts will emerge from it, which we can provisionally name informatism.

A phenomenon favourable to the development of this philosophy would be the emergence of general informatics (as opposed to the technical computer science that dominates today), which would describe different information processing systems - be they computer, natural (biological), or social - at an adequately high level of generality. ${ }^{18}$

13.1. Typical examples of systems that would fall within the scope of general informatics are: a brain, the mind, a living organism, a bank, a university. From some point of view, all of them receive, process, and produce information which is coded in a determined way (for example, in 
the case of the brain, it is a system of neural stimuli and in the case of the mind - images and texts, among other things). ${ }^{19}$

13.2. General informatics (that is, the science of natural and artificial information processing systems) would be a suitable scientific basis for informatism; like today, a scientific basis for the informational worldview is formed by different distributed sciences of information, with (technical) computer science in the lead.

13.3. The essence of philosophical informatism would be the assumption that every being includes some informational and algorithmic content (coded in one way or another), which together with a material substratum determines its specificity. A preliminary task of informatism would be a (definitional) description of this content, taking into consideration various dimensions of the concept of information, including: a) physical (information as an organised structure), b) communication (information as the content of a message), c) epistemological (information as a factor that constructs knowledge) and d) technical (information as computer-processed data).

\section{N O T E S}

${ }^{1}$ For more than two years, different issues connected with the informational worldview have been discussed and developed in the Polish-language academic blog Cafe Aleph (http://marciszewski.eu), as well as in the English-language blog Our Pub (http://blog. calculemus.org), but not so intensively; they were outlined for the first time in the book that I co-edited (with Witold Marciszewski), Umyst - Komputer - Świat. O zagadce umystu $z$ informatycznego punktu widzenia. It should be underlined that these sources and this compendium contain an authorial vision (more precisely: the vision of two authors), which, however, due to discussions in the blog and this monograph, is spreading (and also includes some critical commentaries).

2 Since I indicate these references, I do not include a detailed bibliography in this work. Its extended version can be found in (Marciszewski, Stacewicz 2011) and in the blogs mentioned above (where full texts are also available). In the text, I also mention references to the detailed content of these sources.

${ }^{3}$ From a psychological point of view, one can talk about the worldviews of specific people, however, I would focus on the abstract concept of IWV. This concept is a theoretical construct (types of opinion), a peculiar idealisation that, on the one hand, refers to individual opinions and worldviews (psychological phenomena) and, on the other hand, determines for them an abstract and general point of reference.

4 A more detailed description of these concepts can be found in the book (Marciszewski, Stacewicz 2011, pp. 211-226).

5 On the issue, see for example (Harel 1987).

${ }^{6}$ One of the discussions in the blog Cafe Aleph is devoted to this subject. See Pawel Stacewicz, "Informacyjna piramida" [Informational pyramid], Café Aleph (blog), March 9, 2015, http://marciszewski.eu/?p=7913.

7 Algorithmically unsolvable or uncomputable problems are also called algorithmically inaccessible. This term seems accurate because although, in an objective sense, some 


\section{Pawet Stacewicz}

problems may have solutions (like the Turing machine halting problem), it appears that there is no algorithm (or no algorithm effective enough) which we can use to gain access to knowledge of this solution.

8 On the issue, see (Marciszewski, Stacewicz 2011, pp. 228-230).

9 One of the discussions in the blog Cafe Aleph is devoted to different interpretations of the concept of information. See Paweł Stacewicz, "O informatycznym i ogólnym pojęciu informacji" [On the informational and general concept of information], Café Aleph (blog), March 9, 2015, http://marciszewski.eu/?p=7913.

10 In the book (Marciszewski, Stacewicz 2011), chapters 3, 6 and 13 devoted to this issue; in the blog Cafe Aleph, there is, among other things, an interesting discussion available see Paweł Stacewicz, "O sztucznej inteligencji z Turingiem w tle" [On artificial intelligence with Turing in the background], March 9, 2015, http://marciszewski.eu/?p=1901.

11 Cf. for example (Bobryk 1996) (despite the publication date, the subject is still relevant).

12 This terminological convention is not typical for cognitive science, in which the separation of mind and brain (for example the mind is compared to software, whereas the brain to hardware; see (Newell, Simon 1972)) or the identity of mind and brain (it is then said about the reduction of the mind to the brain; cf. for example (Churchland 1986)) is more often assumed.

The adopted understanding of the mind as a complex, non-reducible system which includes the brain as its fundamental subsystem seems to be more ontologically neutral (it allows asking further questions about separation or reduction), consistent with common sense (mental activities obviously depend on brain processes) and, moreover, strongly connected with analogy (mind - data processing system). Let us note that a data processing system (in a broad sense) always forms a whole composed of both hardware and software (it is not software only).

The adopted convention coincides to some extent with J.R. Searle's proposal (see for example (Searle 1992)).

13 In the book (Stacewicz 2010), I included a detailed study of the subject presented in subpoints $9.1-9.3$.

14 Cf. (Marciszewski, Stacewicz 2011, pp. 115-134).

15 An interesting discussion on the subject matter - initiated by Freeman Dyson and led in the context of living organisms - is available on the Internet. See Freeman Dyson, "Is life analog or digital?," Edge, last modified March 13, 2001, http://edge.org/conversation/islife-analog-or-digital.

16 There is an important fact related to the issue (b) that weakens the thesis about the supermachine power of the human mind. The already identified limitations of computer science do not have to concern all data processing techniques (computational models), but only those which were invented and described (including digital techniques). Therefore, it cannot be excluded that machines of the future - operating on other rules than today - may be at least as cognitively efficient as the human mind.

17 The above-mentioned worldview has deep roots in the philosophical thought of Kurt Gödel that is nowadays described and developed by Witold Marciszewski. Cf. (Marciszewski 2006) and (Marciszewski 2013).

18 On this issue, see (Marciszewski, Stacewicz 2011, pp. 201-205).

19 An interesting issue of similarity between general informatics and the already historical project of cybernetics is emerging here. Perhaps, one could talk about a new "incarnation" of cybernetics, from which computer science developed. Today, located on a different quality level, with new lexis and tools (indeed informational), it can return to the scientific and cultural stage. 
20 According to some introductory explanations, I do not present here a detailed bibliography, which can be found in the blog Cafe Aleph and in the book Umyst - Komputer - Swiat (see footnote 2).

\section{R E F E R E N C E S}

(mentioned directly in the text) $)^{20}$

Cafe Aleph (http://blog.marciszewski.eu/), an academic discussion blog written (in Polish) by W. Marciszewski and P. Stacewicz, which includes many texts, entries and discussions concerning the informational worldview.

Bobryk, J. (1996). Akty świadomości i procesy poznawcze. Warsaw: Wydawnictwo Leopoldinum.

Bolter, J.D. (1984). Turing's Man. Western Culture in the Computer Age. Chapel Hill: The University of North Carolina Press.

Churchland, P.S. (1986). Neuropsychology. Toward a unified science of mind/brain. Cambridge, MA: MIT Press.

Gödel, K. (1931). Über formal unentscheidbare Sätze der 'Principia Mathematica' und verwandter Systeme I. Monatshefte für Mathematik und Physik 38, no. 1, $173-198$.

Gödel, K. (1936). Über die Länge von Beweisen. Ergebnisse eines mathematischen Kolloquiums 7, 23-24.

Harel, D. (1987). Algorithmics: The spirit of computing. Reading, MA: AddisonWesley.

Lindsay, P.H. \& Norman, D.A. (1972). Human Information Processing. Introduction to Psychology. New York: Academic Press.

Marciszewski, W. (2006). The Gödelian Speed-up and Other Strategies to Address Decidability and Tractability. Studies in Logic, Grammar and Rhetoric 9, no. 22 .

Marciszewski, W. \& Stacewicz, P. (2011). Umyst-Komputer - Świat. O zagadce umystu z informatycznego punktu widzenia. Warszawa: Wydawnictwo EXIT.

Newell, A. \& Simon, H.A. (1972). Human Problem Solving. Englewood Cliffs, NJ: Prentice Hall.

Searle J.R. (1992). The Rediscovery of the Mind, Cambridge, MA: MIT Press.

Stacewicz, P. (2010). Umyst a modele maszyn uczacych się, współczesne badania informatyczne $w$ oczach filozofia. Warszawa: Wydawnictwo EXIT.

Russell, S., \& Norvig, P. (1994). Artificial intelligence: A modern approach. Englewood Cliffs, NJ: Prentice-Hall.

Turing, A.M. (1936). On Computable Numbers, with an Application to the Entscheidungsproblem. Proceedings of the London Mathematical Society 40, no. 2, 230-265. 